\title{
Oral health related quality of life in pregnant and post partum women in two social network domains; predominantly home-based and work- based networks
}

\author{
Gabriela A Lamarca ${ }^{1,2^{*}}$, Maria do C Leal ${ }^{1}$, Anna $\Pi$ Leao ${ }^{3}$, Aubrey Sheiham² and Mario V Vettore ${ }^{4}$
}

\begin{abstract}
Background: Individuals connected to supportive social networks have better general and oral health quality of life. The objective of this study was to assess whether there were differences in oral health related quality of life (OHRQoL) between women connected to either predominantly home-based and work-based social networks.

Methods: A follow-up prevalence study was conducted on 1403 pregnant and post-partum women (mean age of 25.2 \pm 6.3 years) living in two cities in the State of Rio de Janeiro, Brazil. Women were participants in an established cohort followed from pregnancy (baseline) to post-partum period (follow-up). All participants were allocated to two groups; 1. work-based social network group - employed women with paid work, and, 2. home-based social network group women with no paid work, housewives or unemployed women. Measures of social support and social network were used as well as questions on sociodemographic characteristics and OHRQoL and health related behaviors. Multinomial logistic regression was performed to obtain OR of relationships between occupational contexts, affectionate support and positive social interaction on the one hand, and oral health quality of life, using the Oral Health Impacts Profile (OHIP) measure, adjusted for age, ethnicity, family income, schooling, marital status and social class.

Results: There was a modifying effect of positive social interaction on the odds of occupational context on OHRQoL. The odds of having a poorer OHIP score, $\geq 4$, was significantly higher for women with home-based social networks and moderate levels of positive social interactions [OR 1.64 (95\% Cl: 1.08-2.48)], and for women with home-based social networks and low levels of positive social interactions [OR 2.15 (95\% Cl: 1.40-3.30)] compared with women with work-based social networks and high levels of positive social interactions. Black ethnicity was associated with OHIP scores $\geq 4$ [OR 1.73 (95\% Cl: 1.23-2.42)].
\end{abstract}

Conclusions: Pregnant and post-partum Brazilian women in paid employment outside the home and having social supports had better OHRQoL than those with home-based social networks.

Keywords: women's health, oral health, quality of life, social support, social networks, occupation

\section{Introduction}

Social networks and social cohesion affect health [1,2]. The perceptions of general health and overall quality of life are influenced by the received social support [3]. Individuals connected to supportive social networks have better general and oral health related quality of life

\footnotetext{
* Correspondence: gabilamarca@ensp.fiocruz.br

'Escola Nacional de Saúde Pública, Fundação Oswaldo Cruz/FIOCRUZ, Rio de Janeiro, BR

Full list of author information is available at the end of the article
}

(OHRQoL) [4]. The current concepts of social networks focus on how structural arrangements of social institutions shape resources available to individuals, and hence, their behavioral and emotional responses [1]. The structure of network ties influences people's health by providing different types and levels of support. Lower social support is associated with more symptoms of depression [5-8] and poor social support is linked to higher mortality rates $[9-11]$.

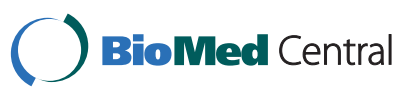

(C) 2012 Lamarca et al; licensee BioMed Central Ltd. This is an Open Access article distributed under the terms of the Creative Commons Attribution License (http://creativecommons.org/licenses/by/2.0), which permits unrestricted use, distribution, and reproduction in any medium, provided the original work is properly cited. 
Berkman and Kawachi argued that social networks operate at the behavioral level through social support and social influence, which affects social engagement and attachment and access to resources and material goods [1]. The concepts of social networks and social supports are intrinsically interconnected and overlap [12]. However, social networks are the structure through which social support is provided [13]. Social support is generally defined in terms of the availability of people who individuals trust, and on whom they can rely on and who will care for them [1]. Research on social support emphasizes the importance of types, frequency, intensity and extent of social networks and on the effects of variation of the individual's social environment [14] as well as on the contexts for developing social networks [1].

The main mechanism that might explain why social support operates via social networks and enhances quality of life is the existence of positive social relationships. Social networks can enhance mood, provide people with a sense of identity, enhance coping strategies and be a source of companionship for sharing activities [4].

Lack of social support is an important risk factor for maternal well-being and quality of life during pregnancy, and has adverse effects on pregnancy outcomes [15]. Some studies on the relationship between social support and health in pregnant women have focused on social support interventions; others were related to family support $[16,17]$. Women with low social support are more likely to report postnatal depression and lower quality of life than well-supported women [18]. Pregnant women with poor social networks were at high risk for emotional and behavioral problems both to mothers and their children [19].

As stated earlier, the contexts for developing social networks affect the quality and quantity of social support. Employed women are healthier than those not employed [20,21]. That suggests that work colleagues can be an important network of social relationships and social support. They are likely to confer health benefits [22]. Social processes in women's daily activities may affect their subjective perceptions of health. In a study of Japanese women workers, poor social networks at work were associated with worse self-perceived health, mainly among older women. Older workers with social networks mainly at work reported better health than those with better social networks at home [23]. Furthermore, there was a positive association between lack of social networks outside the work environment and worse general health among middle-aged women [23]. There is a positive relationship between work-related psychosocial factors such as decision latitude, job demands and social support, and the health of workers [24]. Women in the labor market may perform tasks involving high demand and over which they have little control. That may lead to stress and poorer health. In addition, they may be less intellectually and socially stimulated; aspects considered harmful to health $[25,26]$.

Oral health conditions are associated with social networks and social support [27-29]. The use of dental services was associated with better levels of social networks and social support [27,28]. Men who had more social supports and those reporting having at least one close friend and those who participated in religious activities were less likely to develop periodontitis [30]. Whereas there are numerous studies showing that dental status affects OHRQoL [31-34], there are very few on the relationship between social networks, using social support as a measure of support, and domains of OHRQoL [35].

There are very few studies on OHRQoL in pregnant women. In two studies the prevalence of negative impacts of pregnancy on OHRQoL was about 25\% $[36,37]$. Oral pain during pregnancy had a negative effect on women's quality of life. The most frequently mentioned effects were difficulty in maintaining emotional balance, difficulty eating and difficulty cleaning teeth [36]. As studies showed that social support during pregnancy affected their health and other outcomes, it was considered important to test whether social support from the supportive relationships in the predominant environments of pregnant women, namely home or work contexts, affected their OHRQoL. The study focused on the different domains of social support that women get predominantly from work-related networks compared to those from home-based networks, rather than on the elaboration of the structural aspects of social networks.

The objective of the main study [38], of which this is a part, was that social support and social network affect positively women's health. The specific hypothesis for this study was that predominantly home-based social network women with low social support had poorer perceived OHRQoL than those whose social networks were work-based and had high social support. The objective was to assess whether there were differences in OHRQoL between women connected to either predominantly home-based and work-based social networks. The research sets out to provide insights into the possible associations of predominantly occupational contexts, home or work, linked to social support and OHRQoL in pregnant and post-partum women.

\section{Methods}

A follow-up prevalence study was carried out in two middle-sized cities in the State of Rio de Janeiro, Brazil, to test the relationship of social determinants with pregnancy outcomes and oral health measures [39]. All pregnant women enrolled in a fixed cohort who sought 
prenatal care at the four main public health care units administered by the National Health Care System ("Sistema Unico de Saude - SUS“) were selected and invited to participate in this study. They were a representative sample of $95 \%$ of the women who were pregnant during the study period in both cities.

The sample size was estimated as 1059 subjects based on the prevalence of $59.5 \%$ of the impact of oral health on quality of life, considering OHIP $>1[32,40]$ to detect a $5 \%$ of the differences between groups, with a significance level of $5 \%$ and power of $95 \%$ [41]. A study with $20 \%$ of losses during follow-up required 1270 participants.

Primary data were collected through face-to-face individual structured interviews between October 2008 and December 2009. The information was obtained at baseline (first trimester of pregnancy) and during the 30 days postpartum period (follow-up).

The selection criteria were women in the first trimester of pregnancy and living at their current address for at least 12 months. The latter criterion was used because social networks and social support tend to be stable after some months. First, the interviewers inspected the medical notes and chose pregnant women according to the selection criteria. All eligible pregnant women were invited to participate. They were informed about the objectives of the study. One of the interviewers requested their participation. After obtaining their consent, the women were interviewed. The study was approved by the Committee of Ethics and Research of the National School of Public Health - ENSP/FIOCRUZ (protocol no. 158/06).

\section{Definition of occupational context}

The main exposure was the occupational context, which was considered to be composed of different characteristics of way of life and characteristics related to occupational status.

\section{Groups of comparison}

Participants were allocated to two groups: 1. the workbased social network group were employed women with paid work. 2. the home-based social network group were women with no paid work, housewives or unemployed women. Measures of social support and social network were evaluated to characterize the occupational context.

\section{Social network and social support measures}

Social networks was considered as the "web" of social relationships surrounding the individual as well as their characteristics, or groups of people who have contact with, or with some form of participation [42]. The questionnaire used to assess social networks consisted of 5 questions concerning the person's relationship with family and friends, and their participation in social groups. The instrument has adequate psychometric properties for the Brazilian population [43,44]. Social support was considered as a system of formal and informal relationships through which individuals receive emotional support, material or information to cope with stressful emotional situations [45]. Social support was evaluated using a questionnaire consisting of 19 items comprising five dimensions of functional social support: material (4 questions - provision of practical resources and support material), emotional (3 questions - physical expressions of love and affection), emotional (4 questions - expressions of positive affection, understanding and feelings of confidence), positive social interaction (4 questions - availability of people to have fun or relax), and information (4 questions - availability of people to obtain advice or guidance) [14]. For each item, the women indicated how often they experienced each type of available support: never, rarely, sometimes, often or always. This questionnaire had good reliability for the Brazilian population [44].

\section{The impact of oral health on quality of life}

The outcome was the impact of oral health on quality of life, which reflects the perception of people about dysfunction, discomfort and disability related oral conditions. The validated version of Oral Health Impacts Profile (OHIP-14) for Brazilian population was used to evaluate the experience of impact on oral health on quality of life in the preceding 6 months $[32,40]$. OHIP14 is composed of 14 items, aggregated in 7 dimensions (two items per dimension) as following: functional limitation (items 1 and 2), physical pain (items 3 and 4), psychological discomfort (items 5 and 6), physical disability (items 7 and 8), psychological disability (items 9 and 10), social disability (items 11 and 12) and handicap (items 13 and 14). The overall score was computed by additive method, which is the sum of the individual scores of all items. For each item, the score varied from 0 to 4 : "never" = 0 , "hardly ever" = 1 , "occasionally" $=2$, "often" $=3$, and "very often" = 4. A high score indicates a negative influence of oral health on quality of life.

\section{Covariates}

The covariates were demographic and socioeconomic characteristics, health related behaviors previous and during pregnancy, dental pain in the last 6 months and number of teeth $(<10$ teeth versus $\geq 10$ teeth). Demographic data were maternal age, ethnicity and number of children.

Socioeconomic characteristics were marital status, educational level (years of schooling), familial income, head of the family, housing conditions and social class. 
In this study the term social class refers to the social and economic factors that influence what position(s) individuals and groups hold within the structure of society [46]. A standard social class classification commonly used in Brazil was used [47]. This is an economic classification based on market power comprising a group of specific indicators such as number of bathrooms, number of full-time domestic servants, number of cars owned by the family, possession of domestic items such as television sets, radio sets, VCRs, vacuum cleaners, washing machine, fridges, freezers; and level of education of the head of household. A set of points is assigned to these indicators and a final score defines the socioeconomic groups; A (highest), B, C, D, and E (lowest). Those with the highest scores represented the highest socioeconomic groups.

The health behaviors, assessed before pregnancy, were smoking, cigarette consumption and alcohol consumption. In addition, the Brazilian version of T-ACE questionnaire, based on 5 questions concerning selfperception of drinking habits, was used to assess risky alcohol drinking before pregnancy [48].

\section{Pilot study}

The interviewers were trained to conduct structured and standardized interviews. After training the interviewers, a pilot study was performed to test understanding and layout of questionnaires. Examiners interviewed 40 pregnant selected women at the same health care units of the main study but who were not included in the main study.

\section{Main study}

Data collection was performed by 20 trained interviewers and four fieldwork supervisors. The baseline was conducted in the prenatal health care units to collect occupational context data, social network, social support, demographic and socioeconomic characteristics, number of teeth and health related behaviors. During the baseline interview different strategies were established to reduce the losses to follow-up. First, two telephone numbers were requested. Second, the full current address was registered, including the zip code. Third, contact telephone numbers of the fieldwork supervisors were provided for all women. They were requested to telephone one of the supervisors when admission to the maternity unit or discharge from it was arranged. In addition, they were asked to report if they moved home or changed their telephone number.

The follow-up study was performed in the post partum period immediately after the delivery to collect data on the impact of oral health on quality of life and dental pain in the last 6 months. The interview was conducted in the maternity hospital wards or at the mother's house up to 30 days after discharge. Women who moved home were excluded. In addition, those who had a miscarriage (pregnancy interrupted before the $20^{\text {th }}$ gestational week) or abortion were not re-interviewed.

\section{Data analysis}

All variables were computed for each participant and then for each group. The normal distribution of continuous variables was tested using the Kolmogorov-Smirnov test. Since the continuous variables were not normally distributed, the comparison of groups was performed by Mann-Whitney test. Categorical variables were analyzed by Chi-square test.

Internal consistencies for the OHIP scale and its domains were evaluated by the Cronbach's $\alpha$ coefficient. Cronbachs' $\alpha$ removing each domain of the OHIP were also assessed.

The relationship between occupational context and the impact of oral health on quality of life was tested using multinomial logistic regression. The sample was categorized into 3 groups according to the prevalence and the median (the median of OHIP = 3) of the number of impacts of OHIP: OHIP $=0$ (No impact); OHIP 1 -3 (Scores from 1 to 3 ); OHIP $\geq 4$ (Scores $\geq 4$ ). In addition, the sample was grouped concerning the dimensions of social support. Subjects with low levels of impacts were those with scores equal to zero, moderate level subjects were those between zero and the median, and high level subjects were those above the median.

First, a comparison was made between social support dimensions and types of social networks in the workbased and home-based groups. Social support and social network variables that were statistically different between occupational context groups were included in the bivariate analysis. The crude Odds Ratio (OR) and Confidence Intervals of 95\% were calculated between occupational context and covariates and OHIP groups. Second, multinomial logistic regression was performed to obtain adjusted OR of occupation context, affectionate support, positive social interaction and social network/friends with OHIP adjusted for age, ethnicity, family income, schooling, marital status and social class (Model 1).

To test the statistical significance of interaction between occupational context and potential modifying factors (social support dimensions and social network) the occupational context and covariates were first added to the regression model. After that, the interaction terms 'occupational context $\mathrm{X}$ affectionate support', occupational context $\mathrm{X}$ positive social interaction' and 'occupational context X social network/friends' where added to the model (Model 2). Model 1 (without interaction terms) and Model 2 (with interaction terms) were compared using Likelihood Ratio tests. 
All statistical analyses were performed using the SPSS (Statistical Package for Social Sciences, version 13.0). The significance level for all analysis was 5\% ( $\mathrm{P}=0.05)$.

\section{Results}

Initially 1750 pregnant women were invited to participate. The acceptance rate was $96 \%$. Of the 1680 women interviewed at baseline, $12(0.7 \%)$ declined to participate in the follow-up, 160 (9.5\%) were excluded because they had moved home and 105 (6.3\%) were lost in the follow-up (miscarriage or moved home without informing the fieldwork supervisor). The final sample was 1403 women, $83.5 \%$ of the baseline sample.

Of the 1403 women, 580 (41.3\%) were women in paid employment (work-based social network group) and 823 (58.7\%) were unemployed women or those not doing paid work (home-based social network group). Among the women in paid work, 25 (4.3\%) were civil servants, 342 (59.0\%) were employees, 210 (36.2\%) were selfemployed, and only $3(0.5 \%)$ were employers. Demographic data, socioeconomic and housing conditions characteristics of the occupational context groups are presented in Table 1 . The average age of the sample was $25.2 \pm 6.3$ years; $42.8 \%$ were Brown. The participants were predominantly from low socioeconomic status, married (70.6\%) and in their first pregnancy (47.3\%). Even though most were living in adequate housing conditions, $42.8 \%$ reported lack of sewage and $18.4 \%$ had water supply outside the house.

Women from the work-based social network group were older, had more years of schooling and higher family income compared with women in the homebased social network group. The work-based social network group had more married women, and women who were head of family and from higher (B and C) social classes. The home-based social network group had a higher proportion of women living in houses without general drainage $(\mathrm{P}<0.001)$ and more residents per room $(\mathrm{P}<0.001)$ (Table 1$)$.

The comparison between oral health measures and health related behaviors in work-based women and those with home-based social networks is presented in Table 2. Women from the work-based social network group had lower OHIP-14 scores than those from home-based social network group (3.5 versus 4.0 ), but the statistical significance was borderline. There was no difference in the proportions of women in the two groups with dental pain in the last six months and with 10 teeth or more. The frequency of alcohol intake, alcoholism and smoking was similar in the two groups (Table 2).

There were marked differences in the social support dimensions between occupational context groups (Table 3). Affectionate support and positive social interaction scores were statistically higher in the work-based social network group compared with those in the home-based social network $(\mathrm{P}<0.005)$. There was a borderline association between emotional support and informational support and being in the work-based social network group. Material support scores were similar in the two groups. Different types of social network were assessed. Women in the work-based social network group were more likely to have more friends that they felt comfortable with and could talk to about something ( $\mathrm{P}=0.001$ ). The work-based social network group tended to have a higher proportion of women who participated in religious activities in the past 12 months $(\mathrm{P}=0.064)$. Other types of social networks did not differ between groups (Table 3).

The mean OHIP-14 was $3.8 \pm 7.5$. The Cronbach $\alpha$ coefficient of OHIP-14 was 0.92 . Cronbach $\alpha$ coefficients if OHIP-14 dimensions deleted varied from 0.90 to 0.92 . The OHIP-14 scores were statistically associated with dental pain in the last six months $(\mathrm{P}<0.05)$, and were not associated with the presence of 10 teeth or more.

The association of home-based social network, demographic and socioeconomic characteristic with the impact of oral health on quality of life was initially tested using unadjusted risk estimates [Odds Ratio (OR)] (Table 4). In that analysis, women with OHIP $=0$ (Control group) were the reference category, and the increased odds of having a OHIP score of 1-3 (Group 1) and OHIP score $\geq 4$ (Group 2) was estimated. The frequencies of women with OHIP score 1-3 and OHIP score $\geq 4$ were higher in the home-based social network group compared with those in the work-based social network group (60.7\% versus $39.3 \%$ and $62.5 \%$ versus $37.5 \%$ ). Occupational context, affectionate support, positive social interaction, social network/friends, demographic and socioeconomic characteristics were not associated with OHIP scores 1-3. Women with home-based social networks had significantly higher odds of OHIP score $\geq 4$ [ [OR 1.32 (95\% CI: 1.02 - 1.70)]. Factors associated with OHIP score $\geq 4$ were low family income, Black ethnicity and low social class. The odds of OHIP score $\geq 4$ were significantly higher for women with low levels of affectionate support [OR 1.68 (95\% CI: 1.21 - 2.33)], low positive social interaction [OR 1.71 (95\% CI: 1.25 - 2.35)], family income of two minimal wages or lower [OR 1.35 (95\% CI: 1.04 - 1.74)]. Black ethnicity was related to an increased chance of an OHIP score $\geq 4$ [OR 1.76 (95\% CI: 1.26 - 2.45)]. Social class level $\mathrm{D}$ increased the odds of OHIP score $\geq 4$ [OR 1.95 (95\% CI: 1.03-3.67)] and women in social class level E were 2.52 times more likely to have OHIP scores $\geq 4$ (95\% CI: 1.14 - 5.61) (Table 4).

The results of the final model (Model 2) of the multinomial regression analysis of the association between 
Table 1 Demographic and socioeconomic characteristics; comparisons between work-based and home-based groups

\begin{tabular}{|c|c|c|c|c|}
\hline & $\begin{array}{c}\text { Work-based } \\
\mathrm{N}=580\end{array}$ & $\begin{array}{c}\text { Home-based } \\
\mathrm{N}=823\end{array}$ & $\begin{array}{c}\text { Total } \\
\mathrm{N}=1403\end{array}$ & $P$ value \\
\hline Age, $M(S D)^{a}$ & $26.76 \pm 6.07$ & $24.07 \pm 6.22$ & $25.18 \pm 6.299$ & $<0.001$ \\
\hline Ethnicity ${ }^{b}$ & & & & 0.120 \\
\hline White, $n(\%)$ & $199(34.5)$ & $275(33.5)$ & $474(33.9)$ & \\
\hline Brown, $n(\%)$ & $230(39.9)$ & $369(44.9)$ & $599(42.8)$ & \\
\hline Black, $n(\%)$ & $147(25.5)$ & $178(21.7)$ & $325(23.2)$ & \\
\hline Years of schooling, M (SD) a & $8.28 \pm 2.90$ & $7.42 \pm 2.91$ & $7.78 \pm 2.94$ & $<0.001$ \\
\hline Family income ${ }^{b}$ & & & & $<0.001$ \\
\hline < 1 Minimal wage, $n(\%)$ & $103(17.8)$ & $302(36.7)$ & $405(28.9)$ & \\
\hline 1-2 Minimal wages, $n(\%)$ & $199(34.3)$ & $250(30.4)$ & $449(32.0)$ & \\
\hline$>2$ Minimal wages, $n(\%)$ & $278(47.9)$ & $271(32.9)$ & $549(39.1)$ & \\
\hline Marital status ${ }^{b}$ & & & & 0.003 \\
\hline Married, living with partner, $n$ (\%) & $434(74.8)$ & $557(67.7)$ & 991 (70.6) & \\
\hline Has a partner, not living with him, $n(\%)$ & $111(19.1)$ & $222(27.0)$ & $333(23.7)$ & \\
\hline Single without partner, $n(\%)$ & $35(6.0)$ & $44(5.3)$ & $79(5.6)$ & \\
\hline Social Class ${ }^{\text {b }}$ & & & & $<0.001$ \\
\hline $\mathrm{B}, n(\%)$ & $40(6.9)$ & $43(5.2)$ & $83(5.9)$ & \\
\hline$C, n(\%)$ & $399(68.8)$ & $480(58.3)$ & $879(62.7)$ & \\
\hline $\mathrm{D}, n(\%)$ & $122(21.0)$ & $251(30.5)$ & $373(26.6)$ & \\
\hline$E, n(\%)$ & $19(3.3)$ & $49(6.0)$ & $68(4.8)$ & \\
\hline Head of family ${ }^{b}$ & & & & $<0.001$ \\
\hline Woman, $n(\%)$ & $113(19.5)$ & $48(5.8)$ & $161(11.5)$ & \\
\hline Husband or partner, $n(\%)$ & $341(58.9)$ & $485(58.9)$ & $826(58.9)$ & \\
\hline Other, $n(\%)$ & $120(20.7)$ & $282(34.3)$ & $402(28.7)$ & \\
\hline Number of children ${ }^{b}$ & & & & $<0.001$ \\
\hline No children, $n(\%)$ & $249(42.9)$ & $415(50.4)$ & $664(47.3)$ & \\
\hline 1 child, $n$ (\%) & $203(35.0)$ & $208(25.3)$ & $411(29.3)$ & \\
\hline 2 or more children, $n(\%)$ & $128(22.1)$ & $200(24.3)$ & $328(23.4)$ & \\
\hline Sewage in your house ${ }^{b}$ & & & & 0.016 \\
\hline Lack of sewage or pit sewage, $n(\%)$ & $226(39.0)$ & $374(45.4)$ & $600(42.8)$ & \\
\hline General drainage, $n(\%)$ & $354(61.0)$ & $449(54.6)$ & $803(57.2)$ & \\
\hline Number of residents per room ${ }^{b}$ & & & & $<0.001$ \\
\hline $1, n(\%)$ & $233(40.2)$ & $240(29.2)$ & $473(33.7)$ & \\
\hline $2, n(\%)$ & $244(42.1)$ & $396(48.1)$ & $640(45.6)$ & \\
\hline $3, n(\%)$ & $72(12.4)$ & $124(15.1)$ & $196(14.0)$ & \\
\hline$>3, n(\%)$ & $31(5.3)$ & $63(7.7)$ & $94(6.7)$ & \\
\hline Water supply to house ${ }^{b}$ & & & & 0.352 \\
\hline Water plumbing supply inside the house, $n(\%)$ & $480(82.8)$ & $665(80.8)$ & $1145(81.6)$ & \\
\hline Water plumbing supply outside the house, $n(\%)$ & $100(17.2)$ & $158(19.2)$ & $258(18.4)$ & \\
\hline
\end{tabular}

${ }^{\mathrm{a}}$ Mann-Whitney test ${ }^{\mathrm{b}}$ Chi-square test

occupational context and independent variables with the impact of oral health on quality of life are presented in Table 5 . In the fully adjusted model (Model 1), social network/friends was not associated with home-based social network. Although social network/friends was not statistically associated with home-based social network, the interaction term 'occupational context X social network/friends' was also tested and no association with home-based social network was detected. The association of home-based social network [OR 1.34 (95\% CI:
$0.98-1.85)]$ and moderate positive social interaction [OR 1.31 (95\% CI: 0.99-1.72)] with OHIP score $\geq 4$ was of borderline significance. Low positive social interaction [OR 1.51 (95\% CI: 1.01-2.27)] was significantly associated with OHIP score $\geq 4$ prior to adding the interaction terms (occupational context $\mathrm{X}$ positive social interaction). The interaction term when added to this model (Model 2) was significant, suggesting that positive social interaction modified the occupational context: OHIP relationship (Table 5). Women with work-based 
Table 2 Oral health measures and health related behaviors; comparisons between work-based and home-based groups

\begin{tabular}{|c|c|c|c|c|}
\hline & $\begin{array}{c}\text { Work-based } \\
\mathrm{N}=580\end{array}$ & $\begin{array}{c}\text { Home-based } \\
\mathrm{N}=823\end{array}$ & $\begin{array}{c}\text { Total } \\
\mathrm{N}=1403\end{array}$ & $P$ value \\
\hline \multicolumn{5}{|l|}{ Oral Health Measures } \\
\hline $\mathrm{OHIP}, \mathrm{M}(S D)^{\mathrm{a}}$ & $3.47 \pm 7.29$ & $3.97 \pm 7.60$ & $3.76 \pm 7.47$ & 0.059 \\
\hline Dental pain in last 6 months ${ }^{b}$ & & & & 0.142 \\
\hline No, $n(\%)$ & $364(68.5)$ & $482(64.6)$ & $846(66.2)$ & \\
\hline Yes, $n(\%)$ & $167(31.5)$ & $264(35.4)$ & $431(33.8)$ & \\
\hline Number of teeth ${ }^{b}$ & & & & 0.259 \\
\hline$<10$ teeth, $n(\%)$ & $21(3.6)$ & $40(4.9)$ & $61(4.4)$ & \\
\hline$\geq 10$ teeth, $n(\%)$ & $558(96.4)$ & $780(95.1)$ & $1338(95.6)$ & \\
\hline \multicolumn{5}{|l|}{ Health related behaviors } \\
\hline Alcohol consumption ${ }^{b}$ & & & & 0.213 \\
\hline Do not drink alcohol, $n$ (\%) & $544(93.8)$ & $751(91.3)$ & $1295(92.3)$ & \\
\hline No risk of alcoholism, $n$ (\%) & $25(4.3)$ & $50(6.1)$ & $75(5.3)$ & \\
\hline Risk of alcoholism, $n$ (\%) & $11(1.9)$ & $22(2.7)$ & $33(2.4)$ & \\
\hline Smoking ${ }^{b}$ & & & & 0.061 \\
\hline No, $n(\%)$ & $484(83.4)$ & $654(79.5)$ & $1138(81.1)$ & \\
\hline Yes, $n(\%)$ & $96(16.6)$ & $169(20.5)$ & $265(18.9)$ & \\
\hline Number of cigarettes/day, M (SD) ${ }^{a}$ & $7.27 \pm 8.01$ & $10.56 \pm 12.93$ & $9.35 \pm 11.44$ & 0.136 \\
\hline
\end{tabular}

${ }^{a}$ Mann-Whitney test ${ }^{b}$ Chi-square test

social networks and moderate levels of positive social interaction were 1.98 more likely to have OHIP score 13 compared with women with work-based social networks and high levels of positive social interaction $(95 \%$ CI: 1.02-3.83). The odds of OHIP score $\geq 4$ were significantly higher for women with home-based social networks and moderate levels of positive social interaction [OR 1.64 (95\% CI: 1.08-2.48)], and for women with home-based social networks and low levels of positive social interactions [OR 2.15 (95\% CI: 1.40-3.30)] compared with women with work-based social networks and high levels of positive social interaction. Black ethnicity remained associated with OHIP scores $\geq 4$ [OR 1.73 (95\% CI: 1.23-2.42)]. Model 2 (with interaction terms) was statistically different from Model 1 (without interaction terms) (Chi-Square 18.827, $\mathrm{P}$ value $=0.043)$.

\section{Discussion}

The main finding of this study was the positive association between work-based social networks and better oral health quality of life. The identified interaction between occupational context and social support also showed a gradient in the final model of OHIP. The lower the social support, the higher the odds of having more

Table 3 Comparison of social support dimensions and types of social networks between work-based and home-based groups

\begin{tabular}{|c|c|c|c|c|}
\hline & $\begin{array}{c}\text { Work-based } \\
N=580\end{array}$ & $\begin{array}{l}\text { Home-based } \\
N=823\end{array}$ & $\begin{array}{c}\text { Total } \\
N=1403\end{array}$ & $P$ value \\
\hline \multicolumn{5}{|l|}{ Social support dimensions } \\
\hline Affectionate support, M (SD) ${ }^{a}$ & $93.9 \pm 12.9$ & $91.8 \pm 14.9$ & $92.7 \pm 14.1$ & 0.002 \\
\hline Emotional support, $M(S D)^{a}$ & $62.2 \pm 20.2$ & $60.0 \pm 21.2$ & $61.5 \pm 20.1$ & 0.068 \\
\hline Information support, $M(S D)^{\text {a }}$ & $62.5 \pm 19.9$ & $60.8 \pm 20.2$ & $61.5 \pm 20.1$ & 0.075 \\
\hline Positive social interaction, $M(S D)^{a}$ & $66.9 \pm 17.5$ & $62.9 \pm 20.0$ & $64.6 \pm 19.1$ & $<0.001$ \\
\hline Material support (tangible), M (SD) ${ }^{a}$ & $59.9 \pm 20.4$ & $59.2 \pm 21.2$ & $59.5 \pm 20.9$ & 0.550 \\
\hline \multicolumn{5}{|l|}{ Social network } \\
\hline Relatives, $n$ (\%) & $442(81.4)$ & $625(82.3)$ & $1067(82.0)$ & 0.662 \\
\hline Friends, $n(\%)$ & $346(63.7)$ & $412(54.3)$ & $758(58.2)$ & 0.001 \\
\hline Meetings, $n$ (\%) & $32(5.9)$ & $39(5.1)$ & $71(5.5)$ & 0.554 \\
\hline Charity work, $n(\%)$ & $23(4.2)$ & $28(3.7)$ & $51(3.9)$ & 0.616 \\
\hline Religious, $n$ (\%) & $380(70.0)$ & $494(65.1)$ & $874(67.1)$ & 0.064 \\
\hline
\end{tabular}

\footnotetext{
${ }^{\mathrm{a}}$ Mann-Whitney test ${ }^{\mathrm{b}}$ Chi-square test
} 
Table 4 Crude associations between occupational context, social support dimensions, demographic and socioeconomic characteristics and OHIP

\begin{tabular}{|c|c|c|c|c|c|c|c|}
\hline & $\begin{array}{c}\text { OHIP }=0 \text { (Reference } \\
\text { category) }\end{array}$ & $\begin{array}{c}\mathrm{OHIP}=1- \\
3\end{array}$ & $\begin{array}{l}\text { Crude OR } \\
\text { Cl95\% }\end{array}$ & $\begin{array}{c}\mathrm{P} \\
\text { value }\end{array}$ & OHIP $\geq 4$ & $\begin{array}{l}\text { Crude OR } \\
\text { Cl95\% }\end{array}$ & $\begin{array}{c}P \\
\text { value }\end{array}$ \\
\hline \multicolumn{8}{|l|}{ Occupational context ${ }^{a}$} \\
\hline Work-based, $n$ (\%) & $363(43.8)$ & $66(39.3)$ & 1 & & $114(37.5)$ & 1 & 0.036 \\
\hline Home-based, $n$ (\%) & $466(56.2)$ & $102(60.7)$ & $1.13(0.77-1.66)$ & 0.530 & $190(62.5)$ & $1.32(1.02-1.70)$ & \\
\hline \multicolumn{8}{|l|}{ Social Support } \\
\hline \multicolumn{8}{|l|}{ Affectionate support ${ }^{a}$} \\
\hline High level, $n$ (\%) & $114(13.8)$ & $23(18.4)$ & 1 & & $75(21.6)$ & 1 & \\
\hline Moderate level, $n$ (\%) & $140(16.9)$ & $18(14.4)$ & $0.88(0.51-1.51)$ & 0.639 & $47(13.5)$ & $0.86(0.60-1.23)$ & 0.405 \\
\hline Low level, $n(\%)$ & $574(69.3)$ & $84(67.2)$ & $1.38(0.34-2.28)$ & 0.211 & $225(64.9)$ & $1.68(1.21-2.33)$ & 0.002 \\
\hline \multicolumn{8}{|l|}{ Positive social interaction ${ }^{a}$} \\
\hline High level, $n(\%)$ & $176(21.3)$ & $26(20.8)$ & 1 & & $101(29.1)$ & 1 & \\
\hline Moderate level, $n$ (\%) & $279(33.7)$ & $51(40.8)$ & $1.42(0.93-2.17)$ & 0.104 & $121(34.9)$ & $1.29(0.96-1.74)$ & 0.086 \\
\hline Low level, $n$ (\%) & $373(45.0)$ & $48(38.4)$ & $1.15(0.69-1.91)$ & 0.596 & $125(36.0)$ & $1.71(1.25-2.35)$ & $<0.001$ \\
\hline \multicolumn{8}{|l|}{ Social network/Friends ${ }^{a}$} \\
\hline No friends, $n(\%)$ & $358(43.2)$ & $44(35.2)$ & 1 & 0.093 & $142(40.9)$ & 1 & 0.474 \\
\hline One or more friends, $n(\%)$ & $471(56.8)$ & $81(64.8)$ & $0.72(0.48-1.06)$ & & $205(59.1)$ & $0.91(0.71-1.18)$ & \\
\hline \multicolumn{8}{|l|}{ Age $^{a}$} \\
\hline 13 to $24, n(\%)$ & $439(53.0)$ & $92(54.8)$ & 1 & & $141(46.4)$ & 1 & \\
\hline 25 to $28, n(\%)$ & $390(47.0)$ & $76(45.2)$ & $1.07(0.74-1.56)$ & 0.714 & $163(53.6)$ & $1.19(0.92-1.52)$ & 0.183 \\
\hline \multicolumn{8}{|l|}{ Schooling ${ }^{a}$} \\
\hline$=9, n(\%)$ & $348(42.0)$ & $79(47.0)$ & 1 & & $124(40.8)$ & 1 & \\
\hline 0 to $8, n(\%)$ & $481(58.0)$ & $89(53.0)$ & $1.09(0.74-1.59)$ & 0.670 & $180(59.2)$ & $1.03(0.80-1.33)$ & 0.831 \\
\hline \multicolumn{8}{|l|}{ Familiar income ${ }^{a}$} \\
\hline$>2$ Minimal wages, $n(\%)$ & $439(53.0)$ & $76(60.8)$ & 1 & & $209(60.2)$ & 1 & \\
\hline$=2$ Minimal wages, $n(\%)$ & $390(47.0)$ & $49(39.2)$ & $1.38(0.94-2.02)$ & 0.102 & $138(39.8)$ & $1.35(1.04-1.74)$ & 0.022 \\
\hline \multicolumn{8}{|l|}{ Ethnicity ${ }^{a}$} \\
\hline White, $n(\%)$ & $297(36.0)$ & $49(29.2)$ & 1 & & $87(28.7)$ & 1 & \\
\hline Brown, $n(\%)$ & $345(41.8)$ & $81(48.2)$ & $1.44(0.94-2.20)$ & 0.097 & $128(42.2)$ & $1.28(0.95-1.73)$ & 0.110 \\
\hline Black, $n(\%)$ & $183(22.2)$ & $38(22.6)$ & $0.87(0.50-1.53)$ & 0.638 & $88(29.0)$ & $1.76(1.26-2.45)$ & 0.001 \\
\hline \multicolumn{8}{|l|}{ Marital status ${ }^{a}$} \\
\hline Married living with partner, $n(\%)$ & $579(69.8)$ & $113(67.3)$ & 1 & & $230(75.7)$ & 1 & \\
\hline $\begin{array}{l}\text { Married not living with partner, } n \\
(\%)\end{array}$ & $205(24.7)$ & $44(26.2)$ & $1.17(0.76-1.80)$ & 0.472 & $59(19.4)$ & $0.75(0.55-1.02)$ & 0.064 \\
\hline Single, $n(\%)$ & $45(5.4)$ & $11(6.5)$ & $1.41(0.67-3.00)$ & 0.368 & $15(4.9)$ & $0.84(0.47-1.49)$ & 0.548 \\
\hline \multicolumn{8}{|l|}{ Social Class ${ }^{a}$} \\
\hline $\mathrm{B}, n(\%)$ & $53(6.4)$ & $10(6.0)$ & 1 & & $11(3.6)$ & 1 & \\
\hline C, $n(\%)$ & $533(64.3)$ & $112(66.7)$ & $1.19(0.53-2.71)$ & 0.673 & $175(57.6)$ & $1.44(0.78-2.66)$ & 0.240 \\
\hline $\mathrm{D}, n(\%)$ & $210(25.3)$ & $39(23.2)$ & $1.05(0.43-2.52)$ & 0.921 & $98(32.2)$ & $1.95(1.03-3.67)$ & 0.039 \\
\hline$E, n(\%)$ & $33(4.0)$ & $7(4.2)$ & $1.15(0.34-3.91)$ & 0.826 & $20(6.6)$ & $2.52(1.14-5.61)$ & 0.023 \\
\hline
\end{tabular}

a Chi-square test

negative oral impacts on quality of life. In addition, home-based social network women with moderate positive social interaction had significantly higher odds of having poorer oral health quality of life.

The stratified analysis illustrated the modifying effect of social support. The odds of occupational context on OHIP was higher among women with higher levels of positive social interaction compared with those with lower levels of positive social interaction. It appears that in women with high social support, the importance of occupational context on oral health is more relevant than for those with low social support. This study shows that being employed is not a sufficient condition for having lower impacts on oral health on quality of life. A combination of a higher social support (positive social interaction) and work-based social network appears to be needed to have better OHRQoL.

The observed link between occupational context and social support with oral health was probably related to the marked differences in two social support dimensions 
Table 5 Adjusted associations ${ }^{a}$ between occupational context and levels of positive social interaction, and ethnicity characteristics and OHIP

\begin{tabular}{|c|c|c|c|c|}
\hline & $\mathrm{OHIP}=1-3^{\mathrm{b}}$ & $P$ value & OHIP $\geq 4^{b}$ & $P$ value \\
\hline \multicolumn{5}{|l|}{ Occupational context \& } \\
\hline \multicolumn{5}{|l|}{ Positive social interaction (PI) } \\
\hline Work-based + High level PI & 1 & & 1 & \\
\hline Work-based + Moderate level PI & $1.98(1.02-3.83)$ & $0.043 *$ & $1.35(0.85-2.14)$ & 0.206 \\
\hline Work-based + Low level PI & $1.66(0.73-3.80)$ & 0.228 & $1.70(0.98-2.86)$ & 0.062 \\
\hline Home-based + High level PI & $1.58(0.85-2.94)$ & 0.148 & $1.34(0.90-2.03)$ & 0.162 \\
\hline Home-based + Moderate level PI & $1.75(0.93-3.29)$ & 0.081 & $1.64(1.08-2.48)$ & $0.020 *$ \\
\hline Home-based + Low level PI & $1.33(0.65-2.73)$ & 0.432 & $2.15(1.40-3.30)$ & $<0.001 *$ \\
\hline \multicolumn{5}{|l|}{ Ethnicity } \\
\hline White & 1 & & 1 & \\
\hline Brown & $1.43(0.93-2.19)$ & 0.104 & $1.23(0.91-1.70)$ & 0.186 \\
\hline Black & $0.86(0.49-1.51)$ & 0.603 & $1.73(1.23-2.42)$ & $0.001 *$ \\
\hline
\end{tabular}

in occupational context groups. Higher scores of affectionate support and positive social interaction, domains of social support, were positively associated with predominantly work-based social network women. Even though the findings reflect and reinforce the theory that work improves and facilitates formation of stable social relationships, social support acted as an effect modifier on the relationship between occupational context and OHIP [49]. Based on the theory of benefits of work on health, social support originating from partnerships at work can provide benefits to health and decrease risks of diseases [50]. It has been hypothesized that work environment can offer greater opportunities to build self-esteem and improve confidence in the decision making processes. Employed female workers also have more social support and working increases experiences that enhances satisfactions with life [50].

The positive or negative impacts of formal work on physical and mental health are still a subject of debate. In general health, the relationship between work-related psychosocial factors, such as job control, job strain (high demand and low control), insecurity, and social support and workers' health has been widely reported [51-55]. Most of studies have focused on the association between health and the ways that work is structured in terms of hours of work, continuing education and flexibility to manage work and home demands [24]. On the other hand, occupations with high strain and lack of support at work were closely associated with psychological distress [54]. Concerning oral health outcomes, Marcenes and Sheiham (1992) addressed the relationship between work-related mental demand and periodontal disease [56]. The association of flexibility in working hours with oral health related behaviors and gingival health has also been investigated [57].

Previous evidence suggests that social connections are powerful predictors, and probably affects subjective well-being [58]. The OHIP-14 questionnaire was used as a subjective measure of the impacts of oral disorders and conditions on quality of life. The OHIP aims to evaluate the positive and negative impact of oral health on well-being, considering the social, psychological and biological dimensions. OHIP has been widely used in oral epidemiology studies to evaluate subjective oral health [59]. Our findings highlight the importance of the extent to which oral health problems are experienced by women in different occupational contexts. This study suggests possible mechanisms of how social connections and social support are important and may influence women's quality of life. Our findings agree with those of Hanson et al. (1994), who found that oral health related conditions were associated with social support [29]. Unfavorable socioeconomic circumstances have been associated with poor oral health outcomes regardless the indicator used or the level of analysis [60].

Paid work is the key mechanism through which people obtain important material resources to health, especially income, which in turn, is related to better diet, adequate housing and other material goods [61,62]. In this study, home-based social network women had lower levels of family income and poorer social network compared with work-based social network women. It appears that predominantly home-based women did not have enough social networks to provide sufficient social support. We can hypothesize that home-based social network women are clustered in socially excluded groups; low income 
and less educated women. Because of that, they would have a higher OHIP. However, it can also be argued that the poor oral health quality of life might exclude them from the labor market, thereby excluding them from social interactions, and as a result, provide less social support.

The positive aspects of the present study were the use of questionnaires with adequate psychometric properties for the Brazilian population concerning social support, social network and the impact of oral conditions on quality of life. OHIP presented good psychometrics properties. Furthermore, the data collection was standardized and collected by trained interviewers. In addition, the response rate was high and losses to follow-up were low. The time sequence of the exposure and outcome in this study provides relevant evidence on the potential benefit of work related social networks on oral health.

Although a robust sample was used in this study, our findings are limited to pregnant and post-partum women. Previous studies have shown that social support is higher in pregnant and post-partum women compared to general women in general $[16,17]$. In addition, our findings suggest that social support (positive social interaction) mediates the association between homebased social network and OHIP scores. Therefore, the results should not be generalized.

There is scope for more comprehensive studies on the relationship between work-based social networks and oral health. Detailed information concerning work environment should be collected in future studies, including job quality, hours spending at work and job demand. As the women in the labor market usually perform tasks over which they have little control and high demand, it would be relevant to consider women's sense of coherence in future investigations [50]. Even though paid work had a positive association with oral health, future studies can offer a better understanding about social networks at work and health. For example, the levels of social networks may vary among different types of jobs, and coping strategies may play an important role on health among those under worst job conditions or in workers with low social network at labor market.

\section{Conclusions}

Being in paid employment and having good social support was positively related to oral health related quality of life of women during pregnancy and the post-partum period.

\section{Acknowledgements}

This study was funded by CNPq and FAPERJ (Grant E-26/101.495/2010). We are grateful to all participants who completed the questionnaires.

\section{Author details}

'Escola Nacional de Saúde Pública, Fundação Oswaldo Cruz/FIOCRUZ, Rio de Janeiro, BR. ${ }^{2}$ Department of Epidemiology and Public Health, University College London, London, UK. ${ }^{3}$ Faculdade de Odontologia, Universidade Federal do Rio de Janeiro, Rio de Janeiro, BR. ${ }^{4}$ Instituto de Estudos em Saúde Coletiva, Universidade Federal do Rio de Janeiro, Rio de Janeiro, BR.

\section{Authors' contributions}

$G L$ was involved in design of the study, acquisition of data, analysis and interpretation of the data, interpretation of the results and drafted the manuscript. M do CL helped design the study, interpreted the data and reviewed the manuscript. ATTL was involved in the analysis and interpretation of data and contributed to writing the manuscript. AS was involved with interpretation of the data and revising the manuscript. MV was involved with the conception and design of the study, developed the statistical framework for data analysis, and drafted the manuscript. All authors read and approved the final manuscript.

\section{Competing interests}

The authors declare that they have no competing interests.

Received: 8 December 2010 Accepted: 13 January 2012

Published: 13 January 2012

\section{References}

1. Berkman LF, Kawachi I: Social Epidemiology. New York: Oxford University Press; 2000.

2. Berkman LF, Glass TA, Brissette I, Seeman TE: From social integration to health: Durkheim in the new millennium. Soc Sci Med 2000, 51:843-57.

3. Sawatzky R, Ratner PA, Johnson JL, Kopec JA, Zumbo BD: Self-reported physical and mental health status and quality of life in adolescents: a latent variable mediation model. Health and Quality of Life Outcomes 2010, 8:17.

4. Helgeson VS: Social support and quality of life. Quality of Life Research 2003, 12(Suppl 1):25-31.

5. Bowling A, Browne PD: Social networks, health and emotional well-being among the oldest old in London. J Gerontol 1991, 46:S20-32.

6. Holahah CJ, Moos RH, Holahah CK, Brannan PL: Social support, coping, and depressive symptoms in a late-middle-aged sample of patients reporting cardiac illness. Health Psychol 1995, 14:152-63.

7. Lomauro TA: Social support, health locus-of-control, and coping style and their relationship to depression among stroke victims. Dissertation Abstracts Int 1990, 51(5-b):2628, Doctoral Dissertation, St. John University US.

8. Matt GE, Dean A: Social support from friends and psychological distress among elderly persons: moderatos effects of age. J Health Soc Behav 1993, 34:197-200.

9. Berkman LF, Leo-Summers L, Horwitz Rl: Emotional support and survival following myocardial infarction: a prospective population-based study of the elderly. Ann Intern Med 1992, 117:1003-9.

10. Brummett BH, Barefoot JC, Siegler IC, Clapp-Channing NE, Lytle BL, Bosworth HB, Williams RB Jr, Mark DB: Characteristics of socially isolated patients with coronary artery disease who are at elevated risk for mortality. Psychosom Med 2001, 63(2):267-72.

11. Hibbard $J H$, Pope CR: The quality of social roles as predictors of morbidity and mortality. Soc Sci Med 1993, 36:217-25.

12. Gottlieb BH, Bergen AE: Social support concepts and measures. J Psychosom Res 2010, 69(5):511-20.

13. McDowell I: Measuring Health: a guide to rating scales and questionnaires. New York: Oxford University Press; 32006.

14. Sherbourne CD, Stewart AL: The MOS social support theory. Soc Sci Med 1991, 32:705-14.

15. Elsenbruch S, Benson S, Rücke M, Rose M, Dudenhausen J, PincusKnackstedt MK, Klapp BF, Arck PC: Social support during pregnancy: effects on maternal depressive symptoms, smoking and pregnancy outcome. Hum Reprod 2007, 22(3):869-877.

16. Nuckolls KB, Cassel J, Kaplan BH: Psychosocial assets, life crisis, and the prognosis of pregnancy. Am J Epidemiol 1972, 95:431-441.

17. Orr ST: Social Support and Pregnancy Outcome: A Review of the Literature. Clin Obstet and Gynecol 2004, 47(4):842-855 
18. Webster J, Nicholas C, Velacott C, Cridland N, Fawcett L: Quality of life and depression following childbirth: impact of social support. Midwifery 2011, 27(5):745-9.

19. Kita A: Quality of social network for pregnant women in Japan with focus on parity and family structure. Kobe J Med Sci 2000, 46(3):125-36.

20. Khlat $M$, Sermet $C$, Le Pape A: Women's Health in Relation with their Family and Work Roles: France in the Early 1990s. Soc Sci Med 2000 50:1807-25.

21. Klumb PL, Lampert T: Women, Work, and Well-Being 1950-2000: A Review and Methodological Critique. Soc Sci Med 2004, 58:1007-24

22. Godin I, Kittel F: Differential economic stability and psychosocial stress at work: associations with psychosomatic complaints and absenteeism. Soc Sci Med 2004, 58(8):1543-53.

23. Suzuki E, Takao S, Subranian SV, Doi H, Kawachi I: Work-based social networks and health status among Japanese employees. J Epidemiol Community Health 2009, 63:692-696.

24. Sanders $A E$, Spencer JA: Job characteristics and the subjective oral health of Australian workers. Aust N Z J Public Health 2004, 28(3):259-66.

25. Karasek R, Theorell T: Healthy work: stress, productivity, and the reconstruction of working life. New York, NY: Basic Books; 1990, 89-103.

26. Link BG, Lennon MC, Dohrenwend BP: Socioeconomic Status and Depression: The Role of Occupations Involving Direction, Control and Planning. Am J Soc 1996, 98:1351-87.

27. Rickardsson B, Hanson BS: Social network and regular dental care utilisation in elderly men. Results from the population study "Men born in 1914", Malmo, Sweden. Swed Dent J 1989, 13:151-61.

28. Petersen PE, Nörtov B: General and dental health in relation to life-style and social network activity among 67-year-old Danes. Scand J Prim Health Care 1989, 7(4):225-30

29. Hanson BS, Liedberg B, Owall B: Social network, social support and dental status in elderly Swedish men. Community Dent Oral Epidemiol 1994, 22(5 Pt 1):331-37.

30. Merchant AT, Pitiphat W, Ahmed B, Kawachi I, Joshipura K: A prospective study of social support, anger expression and risk of periodontitis in men. J Am Dent Assoc 2003, 134:1591-96.

31. Locker D: Measuring oral health: a conceptual framework. Community Dent Health 1988, 5:3-18.

32. Slade G, Spencer AJ: Development and evaluation of oral health impact profile. Community Dent Health 1994, 11:3-11.

33. Inglehart MR, Bagramian RA: Oral health-related quality of life: an introduction. In Oral health-related quality of life. Edited by: Inglehart MR, Bagramian RA. Chicago, IL: Quintessence Publishing; 2002:1-6.

34. Naito M, Yusa H, Nomura Y, Nakayama T, Hamajima N, Hanada N: Ora health status and health-related quality of life: a systematic review. $J$ Oral Sci 2006, 48:1-7.

35. Achat H, Kawachi I, Levine S, Berkey C, Coakley E, Colditz G: Social Networks, Stress and Health-Related Quality of Life. Qual Life Res 1998 7(8):735-750.

36. Oliveira BH, Nadanovsky P: The impact of oral pain on quality of life during pregnancy in low-income Brazilian women. J Orofac Pain 2006 20(4):297-305.

37. Wandera MN, Engebretsen IM, Rwenyonyi CM, Tumwine J, Astrøm AN PROMISE-EBF Study Group: Periodontal status, tooth loss and selfreported periodontal problems effects on oral impacts on daily performances, OIDP, in pregnant women in Uganda: a cross-sectional study. Health Qual Life Outcomes 2009, 14:7-10.

38. Leal M do C, Pereira APE, Lamarca GA, Vettore MV: The relationship between social capital, social support and the adequate use of prenatal care. Cad Saude Publica 2011, 27(suppl 2):s237-s253.

39. Kleinbaum DG, Kupper LL, Morgenstein H: Epidemiologic Research. Principles and Quantitative Methods. California, Belmont: Lifetime Learning Publications; 1982

40. Oliveira BH, Nadanovsky P: Psychometric properties of the Brazilian version of the Oral Health Impact Profile-short form. Community Dent Oral Epidemiol 2005, 33:307-14

41. Fleiss JL: Statistical Methods for rates and proportions. New York: John Wiley \& Sons; 21981.

42. Berkman LF, Syme SL: Social networks, host resistance and mortality: a nine year follow-up study of Alameda County residents. Am J Epidemiol 1979, 109:186-204.
43. Chor D, Griep RH, Lopes C, Faerstein E: Medidas de rede e apoio social no Estudo Pró-Saúde: pré-testes e estudo piloto. Cad Saúde Pública 2001, 17(4):887-896

44. Griep RH, Chor D, Faerstein E, Lopes C: Apoio social: confiabilidade testereteste de escala no Estudo Pró-Saúde. Cad Saúde Pública 2003, 19(2):625-634

45. Caplan G: Support Systems and Community Mental Health. New York: Behavioral Publications; 1974

46. Lynch JW, Kaplan GA: Socioeconomic position. In Social epidemiology. Edited by: Berkman LF, Kawachi I. New York: Oxford University Press; 2000:13-35.

47. Associação Nacional de Empresas de Pesquisa (ANEP): Critério de Classificação Econômica Brasil. Manual - Anep. São Paulo; 1997.

48. Sokol RJ, Martier SS, Ager JW: The T-ACE questions: Practical prenatal detection of risk-drinking. Am J Obs Gyn 1989, 160:863-871.

49. Wadsworth MEJ: The imprint of time. Oxford: Oxford University Press; 1991

50. Sorensen G, Verbrugge LM: Women, work, and health. Annu Rev Public Health 1987, 8:235-251.

51. Stansfeld SA, Fuhrer R, Head J, Ferrie J, Shipley M: Work and psychiatric disorder in the Whitehall II Study. J Psychosom Res 1997, 43(1):73-81.

52. Quinlan M, Mayhew C, Bohle P: The global expansion of precarious employment, work disorganization, and consequences for occupational health: placing the debate in a comparative historical context. Int $J$ Health Serv 2001, 31(3):507-36.

53. Bosma $H$, Marmot MG, Hemingway H, Nicholson AC, Brunner E, Stansfeld SA: Low job control and risk of coronary heart disease in Whitehall II (prospective cohort) study. BMJ 1997, 314(7080):558-65.

54. Lopes CL, Araya R, Werneck GL, Chor D, Faerstein E: Job strain and other work conditions: relationships with psychological distress among civil servants in Rio de Janeiro, Brazil. Soc Psychiat Epidemiol 2010, 45:345-354.

55. Alves MG, Chor D, Faerstein E, Werneck GL, Lopes CS: Job strain and hypertension in women: Estudo Pro-Saúde (Pro-Health Study). Rev Saude Publica 2009, 43(5):893-6

56. Marcenes WS, Sheiham A: The relationship between work stress and oral health status. Soc Sci Med 1992, 35(12):1511-20.

57. Abbegg C, Croucher R, Marcenes WS, Sheiham A: How do routines of daily activities and flexibility of daily activities affect tooth-cleaning behaviour? J Public Health Dent 2000, 60(3):154-8.

58. Stiglitz JE, Sem A, Fitoussi JP: Report by the Commission on the Measurement of Economic Performance and Social Progress. 2009 [http://www.hqlo.com/content/10/1/5].

59. Slade GD, Sanders AE: ICF and oral health. ICF Australian User Guide Version 1.0. AIHW Catalogue No.: DIS 33. Disability Series Camberra (ACT): Australian Institute of Health and Welfare; 2003.

60. Pattussi MP: Neighbourhood social capital and oral health in adolescents PhD Thesis Epidemiology and dental Public Health Department, University College London; 2004

61. Broom DH, D'Souza RM, Strazdins L, Butterworth P, Parslow R, Rodgers B: The lesser evil: bad jobs or unemployment? A survey of mid-aged Australians. Soc Sci Med 2006, 63(3):575-86.

62. Siegrist J: Place, social exchange and health: proposed sociological framework. Soc Sci Med 2000, 51(9):1283-93.

doi:10.1186/1477-7525-10-5

Cite this article as: Lamarca et al:: Oral health related quality of life in pregnant and post partum women in two social network domains; predominantly home-based and work-based networks. Health and Quality of Life Outcomes 2012 10:5. 